\title{
Effects of human disturbance on a burrow nesting seabird
}

\section{Efectos de la presencia de humanos en aves marinas que anidan en madrigueras}

\author{
Yuri V. Albores-Barajas ${ }^{1,2} \otimes$ and Cecilia Soldatini ${ }^{2}$ \\ ${ }^{1}$ Faculty of Biological and Life Sciences, University of Glasgow, Glasgow G12 8QQ, UK. \\ ${ }^{2}$ Department of Environmental Sciences, University Ca' Foscari of Venice Campo della Celestia, Castello 2737/b. 30122 Venezia, Italy. \\ \yalbores@unive.it
}

\begin{abstract}
During 2004, we followed 72 natural burrows to determine the effects of disturbance on breeding success of Cassin's auklets (Ptychoramphus aleuticus). We used distance from a human settlement or path in the analysis of disturbance. Birds whose burrows were closer to the path or the village had a higher rate of nest abandonment and lower breeding success compared to birds nesting further away from the path or the village. Also, older and more experienced individuals represented a larger proportion of the breeding population on less disturbed areas than on highly disturbed ones, probably as older individuals tend to arrive earlier at the breeding grounds, and failed breeders may change burrow sites to move away from disturbance. P. aleuticus are adversely affected by human activity at colonies even if birds are not handled and burrows are not opened, and this has implications for conservation, and planning of ecotourism. On the long term, this can have negative consequences for this species and others with similar characteristics.
\end{abstract}

Key words: human disturbance, Ptychoramphus aleuticus, breeding success, occupancy, island conservation.

Resumen. Durante el 2004 seguimos 72 nidos de la alcuela (Ptychoramphus aleuticus) para determinar los efectos de disturbio en el éxito reproductivo. Utilizamos la distancia del nido a áreas asentamientos humanos o al camino como medidas de disturbio. Los nidos que estaban más cerca de los asentamientos o del camino tuvieron una tasa de abandono mayor y un éxito reproductivo menor en comparación con los nidos que estaban más alejados de las fuentes de disturbio. También observamos que en las zonas menos expuestas la proporción de adultos, con mayor experiencia, era más alta, posiblemente porque los individuos con mayor experiencia llegan antes a la zona de anidación. Las alcuelas son afectadas negativamente por la presencia de los humanos y sus actividades, aunque las aves no entren en contacto directo con los humanos. A largo plazo, esto puede acarrear consecuencias graves para esta especie y otras con características similares.

Palabras clave: disturbio humano, Ptychoramphus aleuticus, éxito reproductivo, ocupación, conservación de islas.

\section{Introduction}

Damaging activities in the coastal zone, as elsewhere, require careful management to minimise impacts on flora and fauna and such management is best informed by a detailed knowledge of how species of interest are being affected. The rapid growth of wildlife-based tourism and recreation activities presents opportunities for significant economic benefits but also raises concerns about the potential effects on many seabird colonies (Anderson and Keith, 1980). Disturbance of wildlife is of important concern if it affects survival and breeding success, thus leading to a decrease in the population (Blanc et al., 2006). Negative effects on seabird reproduction can be through direct destruction of nests or their contents and the desertion of offspring, particularly at locations where seabirds nest

Recibido: 19 octubre 2010; aceptado: 11 abril 2011 in association with or near to colonies of avian predators (Burger and Gochfeld, 1991; Fernandez-Juricic et al., 2001; Langston et al., 2007). Non-consumptive activities, such as eco-tourism, bird-watching, jogging, etc., may have impacts that are lower than those caused by extraction activities (such as hunting or egg harvests), however, in the long term, the population may be subjected to pressures that cause decreases in numbers, or a reduction in their range size (Robert and Ralph, 1975; Safina and Burger, 1983). On the other hand, disturbance can theoretically lead to an increase in a non-target population, e.g. disturbance of a predator may relax pressure on its prey.

The presence of researchers may cause disturbance too. Some authors report that this disturbance is minimal and can be neglected (Hull and Wilson, 1996), or that there is an increase in the chick loss rate but there is no statistical evidence of effects on chick growth (Gillet et al., 1975); others report that there is a reduction in chick productivity, but this effect remained just for 1 year after the disturbance 
event and then disappeared (Saffer et al., 2000). Also, birds can become adapted to human presence and the behavioral response decreases (Walker et al., 2006) after a time exposed to such "benign" disturbance, and some researchers have even suggested to increase the number of visitors to a colony of seabirds to speed up the process of habituation (Nisbet, 2000). However, species differ in their sensitivity to human disturbance and, although birds may habituate to visitors, inappropriate intrusions at poorly managed sites may result in adverse effects on breeding individuals (Beale, 2007).

In order to quantify disturbance effects, it is important to separate short term disturbance effects, such as flushing, stopping feeding, etc., from long term effects that would lead to a decrease in the population. It is difficult to analyse behavioral responses to disturbance in burrow nesting species, and these behavioral responses may not be the best method when studying the effects of disturbance on birds (Gill et al., 2001). Therefore the approach we used to test effects of human disturbance was to test for differences in breeding success between sites with different levels of exposure to disturbance within a single colony. We studied the effect that human presence, in terms of ecotourism, research, or fishermen presence, may have on a breeding seabird colony, of Ptychoramphus aleuticus (Cassin's auklet), on the San Benito Islands located on the Pacific coast of Mexico. The effects were considered in terms of breeding success reduction and site selection.

\section{Materials and methods}

Study site and species. The San Benito Islands are located on the central west coast of Baja California, in the Mexican Pacific. They comprise 3 islands, East, Middle and West, with the west island hosting a temporary fishing camp.

Ptychoramphus aleuticus is a burrow nesting alcid that is distributed from the Aleutian islands in Alaska to the Baja California Peninsula in Mexico. Its conservation status is "Least Concern" (IUCN, 2009). In the northern part of its range, Cassin's auklets lay 1 single egg per breeding season, while in the southern part of the range they can lay 2 single-egg broods.

From the $6^{\text {th }}$ of February to the $26^{\text {th }}$ of May in 2004, 72 natural burrows were followed using an infrared camera mounted on a plastic probe (for detailed description see Keitt et al., 2003). The infrared camera was introduced into the burrow and the contents were recorded every 5 days. The examination of the burrow took an average of 2 minutes. Only occupied burrows, with an egg inside, were selected as we wanted to establish breeding success and not percentage of occupied natural burrows. It was possible to differentiate the first from the second brood as a second egg was observed either in presence of another egg or when a new egg was laid after a fledging.

Burrow clusters were selected at 3 distances from the fishing village and from the path that is regularly frequented by fishermen and by tourists; the later coming on boats from San Diego, following the migration of the grey whale, and who stop at the island for a walk to see the local fauna for 6-8 hours. Nine burrow clusters were selected (Fig. 1). Within each cluster we selected 8 occupied burrows. Each burrow was marked with a stick and flag for easy identification. In total, 24 burrows were used for each of 3 disturbance levels: burrows in the low disturbance group were located more than $100 \mathrm{~m}$ from the path (triangles on Fig. 1), medium disturbed burrows were located between 50 and $90 \mathrm{~m}$ from the path (stars on Fig. 1) and highly disturbed burrows were at a distance closer than $30 \mathrm{~m}$ from the path or the village (circles on Fig. 1). We are confident that these study groups experience strongly different levels of human disturbance as the human activity in the settlement and on the paths has been consistent for several years, and very few fishermen or tourists deviate from the paths, so that burrows away from the path remain undisturbed.

Due to the nocturnal habits of the $P$. aleuticus, it is relatively easy to catch them at night using a headlamp, as they are disoriented by the light and stay on the ground. We caught birds in the areas of the burrow clusters, assuming the individual would breed on that cluster. We recorded

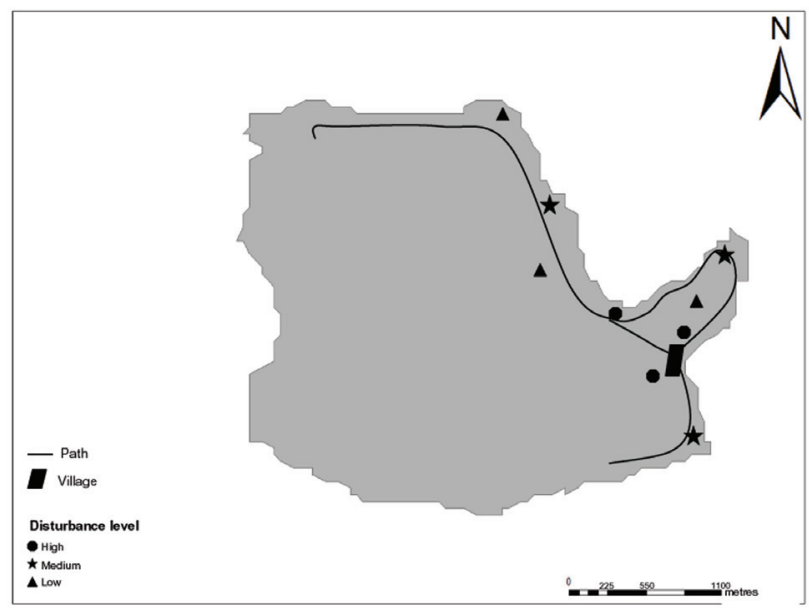

Figure 1. Distribution of the burrow clusters followed during this study. High disturbance areas are represented with diamonds, while medium disturbance zones are represented with stars and low disturbed areas with triangles. The path followed by tourists and fishermen as well as the fishing camp are also marked. Most of the burrow clusters on the island are located in this areas as he rest is occupied by hills. 
eye colour of the birds caught as an estimate of their age (Manuwal, 1978). Physical characteristics of the burrows (depth, orientation of the tunnel, vegetation cover at the entrance) and the burrow cluster (soil type, distance from the sea, slope) were recorded as these factors have been reported to affect breeding success of burrow nesting seabirds (Thompson and Furness, 1991; Velando and Freire, 2003).

Analysis was done using contingency tables to test for differences within broods, and ANOVA's at a significance level of 0.05 to test for differences among the different levels of disturbance. Multiple regression analysis was used to estimate the effects of the physical characteristics of the burrow on the breeding output of the pair occupying that burrow. Statistical packages used for these analyses were SPSS and Statistica (StatSoft, 2003).

\section{Results}

The physical characteristics of the burrows did not have an influence on the breeding output and there were no differences in the depth of the burrow for each level of disturbance $\left(\mathrm{R}^{2}=0.04, p=\mathrm{NS}\right)$. Most of the birds in the low disturbance group were older breeders (at least 3 years old), and a significantly higher proportion of older individuals was recorded in low disturbance areas while there was a close to equality proportion of older and younger breeders ( $<3$ years old $)$ in areas with high disturbance $(\mathrm{N}=47, p<0.001)$ (Fig. 2). There were no significant differences in hatching success at different levels of disturbance $\left(\mathrm{F}_{2,69}=0.74, p=0.39\right)$, but burrows in more disturbed areas had significantly lower breeding success $\left(\mathrm{F}_{2,69}=4.47, p=0.01\right.$; Fig. 3$)$.

When comparing the first and the second broods, most of the pairs in the first brood fledged a chick, while the vast majority of pairs that attempted a second brood failed $\left(\chi^{2}=13.71, p=0.001\right)$. In the first brood there were no significant differences between the different levels of disturbance when comparing the number of eggs abandoned $\left(\chi^{2}=21.5, p=0.51\right)$ or chick mortality $\left(\chi^{2}=13 / 78, p=0.87\right)$, but fledging success was lower in the most disturbed areas $\left(\chi^{2}=27.4 p=0.051\right)$.

\section{Discussion}

We did not find any differences in hatching success between the 3 levels of disturbance, but there were differences in fledging success. Chicks may have been more susceptible to disturbance, as they were subjected to it every day, while adults alternated incubation and experience disturbance every other day only during the incubation period. We found more abandoned burrows

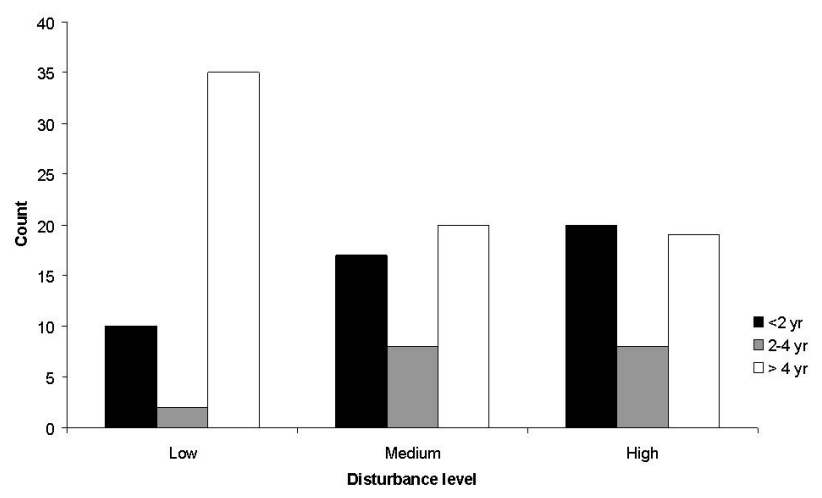

Figure 2. Hatching and fledging success (mean \pm S.E.). There are no differences in hatching success, but fledging success is significantly lower in the highly disturbed burrows, closer to the path or the village.

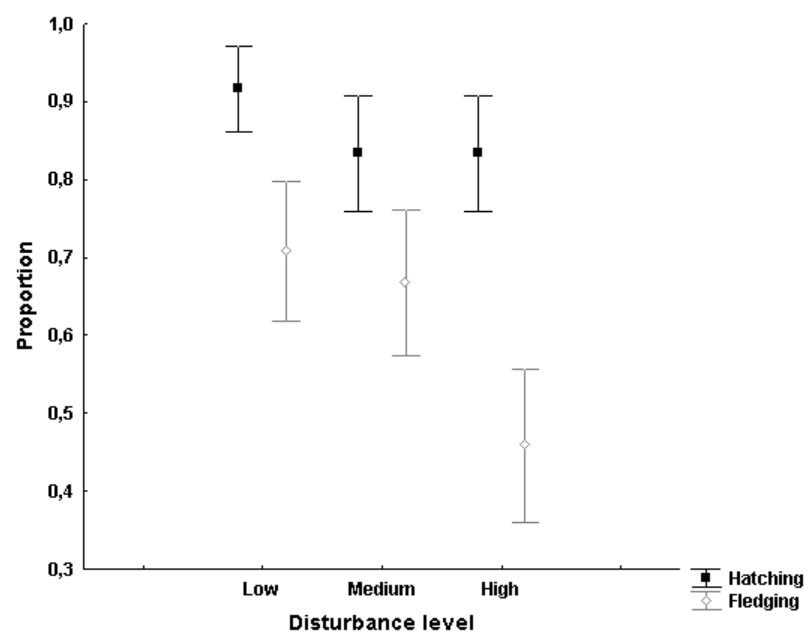

Figure 3. Age distribution according to disturbance level. Most of the immature-eye coloured birds are in burrows where disturbance is high, while on undisturbed burrows the proportion is equal.

with a chick on highly disturbed areas. On a subsequent experimental study (Albores-Barajas et al., 2009), the effects of disturbance appeared to be cummulative and observed only at the end of the season. A similar occurence may take place for burrows on highly disturbed areas, where we observed the differences only on fledging success, but not on hatching success.

As in many other studies (Roberts and Evans, 1993; Klein et al., 1995; Gutzwiller et al., 1998; FernandezJuricic et al., 2003; Taylor and Knight, 2003; Mullner et al., 2004; Laursen et al., 2005), we found an influence of the distance at which birds exhibited a response to the disturbing source. However, experienced birds may cope with this by breeding in burrow clusters further away from the path (Fig. 2). As in other studies, older and more 
experienced individuals were found in better quality sites (Forbes et al., 2000; Pyle et al., 2001). We infer that birds tend to return to the same burrow if they were successful, or will move to a different one if they fail, as observed in shearwaters (Thompson and Furness, 1991). Older and more experienced breeders tend to arrive earlier in the season compared to first time breeders (Greig et al., 1983; Forslund and Part, 1995; Mauck et al., 2004), having a wider option of burrows available. The fact that older and more experienced individuals occupy the majority of the burrows on the low disturbance area may suggest that $P$. aleuticus choose to breed far from human disturbance, while younger individuals are prone to use the burrows closer to the disturbance source. The lack of an effect of the physical characteristic of the nesting grounds on breeding success (Velando and Freire, 2001; Velando and Freire, 2003) suggests that $P$. aleuticus individuals cope with disturbance by staying further away from the disturbance source, rather than digging a deeper burrow or choosing a certain soil composition.

Habituation to walkers has been reported for several species (Nisbet, 2000). For instance, Burger (1998) found that common terns were not too responsive if people remained on marked paths; however, birds showed a strong response if people left the path. Nisbet (2000) even recommends a higher exposure of seabird colonies to disturbance in order to speed up the process of habituation.

Tourism is expected to increase in the near future along the peninsula of Baja California, and a part of the tourist flow will be directed towards the San Benito Islands. Although habituation is a possibility, we feel that the management scheme recommended for Patagonian natural areas (Yorio et al., 2001) could be adapted to this area. The most important aspect, above all, is to have sound scientific information at the base of the management decisions (Velarde and Anderson, 1994). Therefore, we recommend that a better control of the number of visitors is imposed on the island, either by keeping some areas with larger numbers of burrows off limits, or by closing the island during the breeding season, as both of which have a positive effect for breeding birds.

\section{Aknowledgements}

This study was conducted as part of the research required for the degree of $\mathrm{PhD}$ for Y.V.A, funded by Consejo Nacional de Ciencia y Tecnologia, Mexico. We are grateful to Robert W. Furness for his support and comments on the MS; to Grupo de Ecología y Conservación de Islas, for all their support during the development of this study and to PNA Cedros for their logistic support in the field.

\section{Literature cited}

Albores-Barajas, Y. V., C. Soldatini and R. W. Furness. 2009. Are Burrow Nesting Seabird Chicks Affected by Human Disturbance? Waterbirds 32:572-578.

Anderson, D. W. and J. O. Keith. 1980. The human influence on seabird nesting success - conservation implications. Biological Conservation 18:65-80.

Beale, C. M. 2007. Managing visitor access to seabird colonies: a spatial simulation and empirical observations. Ibis 149(s1):102-111.

Blanc, R., M. Guillemain, J. Mouronval, D. Desmonts and H. Fritz. 2006. Effects of non-consumptive leisure disturbance to wildlife. Revue d'Ecologie- La terre et la vie 61:117-133.

Burger, J. 1998. Effects of motorboats and personal watercraft on flight behavior over a colony of common terns. Condor 100:528-534.

Burger, J. and M. Gochfeld. 1991. Human disturbance and birdstolerance and response distances of resident and migrant species in India. Environmental Conservation 18:158-165.

Fernandez-Juricic, E., M. D. Jimenez and E. Lucas. 2001. Alert distance as an alternative measure of bird tolerance to human disturbance: implications for park design. Environmental Conservation 28:263-269.

Fernandez-Juricic, E., A. Sallent, R. Sanz and I. RodriguezPrieto. 2003. Testing the risk-disturbance hypothesis in a fragmented landscape: Nonlinear responses of House Sparrows to humans. Condor 105:316-326.

Forbes, L. S., M. Jajam and G. W. Kaiser. 2000. Habitat constraints and spatial bias in seabird colony distributions. Ecography 23:575-578.

Forslund, P. and T. Part. 1995. Age and Reproduction in Birds - Hypotheses and Tests. Trends in Ecology \& Evolution 10:374-378.

Gill, J. A., K. Norris and W. J. Sutherland. 2001. Why behavioural responses may not reflect the population consequences of human disturbance? Biological Conservation 97:265-268.

Gillet, W. H., J. L. Hayward Jr. and J. F. Stout. 1975. Effects of human activity on egg and chick mortality in a glaucouswinged gull colony. Condor 77:492-495.

Greig, S. A., J. C. Coulson and P. Monaghan. 1983. Age-Related Differences in Foraging Success in the Herring Gull ( Larus argentatus ). Animal Behaviour 31:1237-1243.

Gutzwiller, K. J., H. A. Marcum, H. B. Harvey, J. D. Roth and S. H. Anderson. 1998. Bird tolerance to human intrusion in Wyoming montane forests. Condor 100:519-527.

Hull, C. L. and J. Wilson. 1996. The effect of investigators on the breeding success of royal, Eudyptes schlegeli, and rockhopper penguins, E. chrysocome, at Macquarie Island. Polar Biology 16:335-337.

IUCN. 2009. "IUCN Red List of Threatened Species." Version 2009.1. Retrieved from www.iucnredlist.org.; 2.VII.2009. 
Keitt, B. S., B. R. Tershy and D. A. Croll. 2003. Breeding biology and conservation of the Black-vented Shearwater Puffinus opisthomelas. Ibis 145:673-680.

Klein, M. L., S. R. Humphrey and H. F. Percival. 1995. Effects of ecotourism on distribution of waterbirds in a wildlife refuge. Conservation Biology 9:1454-1465.

Langston, R. H. W., D. Liley, G. Murison, E. Woodfield and R. T. Clarke. 2007. What effects do walkers and dogs have on the distribution and productivity of breeding European Nightjar Caprimulgus europaeus? Ibis 149(s1):27-36.

Laursen, K., J. Kahlert and J. Frikke. 2005. Factors affecting escape distances of staging waterbids. Wildlife Biology 11:13-19.

Manuwal, D. A. 1978. Criteria for Aging Cassin Auklets. BirdBanding 49:157-161.

Mauck, R. A., C. E. Huntington and T. C. Grubb. 2004. Agespecific reproductive success: Evidence for the selection hypothesis. Evolution 58:880-885.

Mullner, A., K. E. Linsenmair and M. Wikelski. 2004. Exposure to ecotourism reduces survival and affects stress response in hoatzin chicks (Opisthocomus hoazin). Biological Conservation 118:549-558.

Nisbet, I. C. T. 2000. Disturbance, habituation, and management of waterbird colonies - Commentary. Waterbirds 23:312-332.

Pyle, P., W. J. Sydeman and M. Hester. 2001. Effects of age, breeding experience, mate fidelity and site fidelity on breeding performance in a declining population of Cassin's auklets. Journal of Animal Ecology 70:1088-1097.

Robert, H. C. and C. J. Ralph. 1975. Effects of human disturbance on the breeding success of gulls. Condor 77:495-499.

Roberts, G. and P. R. Evans. 1993. Responses of foraging sanderlings to human approaches. Behaviour 126:29-43.

Saffer, V. M., J. S. Bradley, R. D. Wooller and C. E. Meathrel. 2000. The effect of human activity on the growth rates of short-tailed shearwater Puffinus tenuirostris chicks. Emu 100:49-53.

Safina, C. and J. Burger. 1983. Effects of human disturbance on reproductive success in the black skimmer. Condor 85:164-171.

StatSoft, I. 2003. STATISTICA (data analysis software system), version 6.

Taylor, A. R. and R. L. Knight. 2003. Wildlife responses to recreation and associated visitor perceptions. Ecological Applications 13:951-963.

Thompson, K. R. and R. W. Furness. 1991. The influence of rainfall and nest-site quality on the population-dynamics of the Manx Shearwater Puffinus puffinus on Rhum. Journal of Zoology 225:427-437.

Velando, A. and J. Freire. 2001. How general is the centralperiphery distribution among seabird colonies? Nest spatial pattern in the European Shag. Condor 103:544-554.

Velando, A. and J. Freire. 2003. Nest site characteristics, occupation and breeding success in the European Shag. Waterbirds 26:473-483.

Velarde, E. and D. W. Anderson. 1994. Conservation and management of seabird island in the Gulf of California: setbacks and successes. In Seabirds on islands: threats, case studies and action plans, D. N. Nettleship, J. Burger and M. Gochfeld (eds.). BirdLife International. Cambridge. p. 229243.

Walker, B. G., P. D. Boersma and J. C. Wingfield. 2006. Habituation of adult magellanic penguins to human visitation as expressed through behavior and corticosterone secretion. Conservation Biology 20:146-154.

Yorio, P., E. Frere, P. Gandini and A. Schiavini. 2001. Tourism and recreation at seabird breeding sites in Patagonia, Argentina: current concerns and future prospects. Bird Conservation International 11:231-245. 